\title{
A Tribute to Robert W. Rieber, Ph.D., Founding Editor, Journal of Psycholinguistic Research
}

\author{
Rafael Art. Javier ${ }^{1}$
}

Published online: 21 February 2021

(c) The Author(s), under exclusive licence to Springer Science+Business Media, LLC part of Springer Nature 2021

\section{DRAFT (copyedited by CB)}

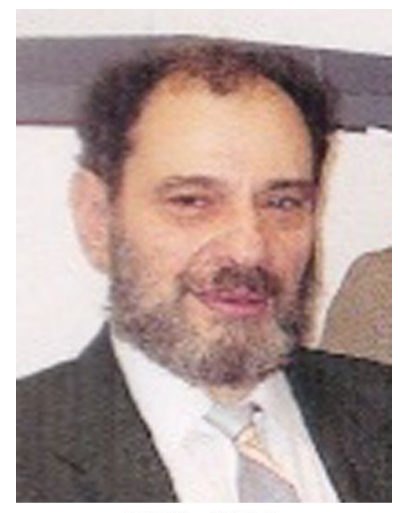

1932-2015

In 1971 the Journal of Psycholinguistic Research launched its first issue under its Founding Editor, Dr. Robert W. Rieber. A speech pathologist and psychologist by training, Dr. Rieber sought to design an interdisciplinary journal that created a line of inquiry that allowed for the complexity of language to be explored in all its manifestations present in human transactions. In this regard, he wanted to encourage submissions that not only included empirical studies with innovative methodologies, but also theoretical manuscripts that introduced innovative models to explain linguistic processes and communicative behaviors that impacted on cognitive and affective developments. His expectation, as stated in that first issue, was that manuscripts accepted "must add to knowledge in some way, whether they are in the form of experimental reports, review papers, or theoretical

Rafael Art. Javier

JAVIERR@stjohns.edu

1 New York, USA 
papers... and studies with negative results," provided that they are of sufficiently high quality to make an original contribution.

Faithful to that basic framework, the Journal of Psycholinguistic Research has, over its 50 years, established itself as one of the most prestigious and influential journals in the scientific community by publishing manuscripts on theoretical and experimental studies of the communicative process, on social and anthropological aspects of communication, on the development of speech and language, on semantics aspects of the communicative process, on biological foundations of communications, on psychopathological aspects of the communication process, and on educational psycholinguistics.

For our 50th year celebration we are seeking to publish manuscripts that advance further Dr. Rieber's vision and legacy by addressing not only fundamental issues on psycholinguistics, but also other language-related issues emerging from new understanding of neurolinguistic developments and technological advancements as well as the role of cultural influences in these processes. Manuscripts examining the impact of these advancements on cognitive and affective processes, language development, learning, linguistic codification of personal and nonpersonal memories in monolingual and multilanguage contexts, and other issues related to communicative functions are welcomed and strongly encouraged. Also encouraged are manuscripts that focus on the scientific application of linguistic analyses to forensic (criminal) issues and to the understanding and deciphering of the language of terrorism as transmitted through online communications.

With that in mind, you will find a series of special issues throughout this year of celebration and beyond meant to highlight some of the innovative and meticulous analyses our scientific community has been engaged in to address some of the issues referred to above. These special issues are also meant to emphasize our determination to continue encouraging manuscripts on communicative processes with innovative approaches. Our goal is to continue serving our scientific community as a preeminent venue for scholarly publications and remain faithful to our outstanding leadership to scholars from all over the world. On behalf of our advisory and editorial board, thank you for your continuous involvement with the journal and for making possible the high caliber of publications in our journal.

Hope you find these publications as exciting and intriguing as we do.

Rafael Art. Javier, Ph.D., ABPP.

Editor-in-Chief. 